Madrygal. Revista de Estudios Gallegos

ISSN: 1138-9664

\title{
A cultura e a lingua galegas en Madrid: o labor do Centro de Estudos Galegos durante o curso 2018-2019
}

Paula Cousillas Pena ${ }^{1}$

Como se veu traballando durante os últimos anos, no Centro de Estudos Galegos (CEG) da Universidade Complutense de Madrid apostamos unha vez máis por diferentes actividades culturais que permitan a difusión da lingua e da cultura galegas desde diferentes espazos e perspectivas.

Así, e en primeiro lugar, debemos salientar o XII Congreso da Asociación Internacional de Estudos Galegos (AIEG), pois rematamos o curso 2017-2018 e á súa vez iniciamos en setembro o curso 2018-2019 coa celebración do XII Congreso da AIEG na Facultade de Filoloxía da Universidad Complutense de Madrid ${ }^{2}$. A directora do CEG, Carmen Mejía, xunto co seu equipo, organizou este congreso titulado Novos horizontes para unha Galicia Global: redes, territorio e memoria, baixo o lema "Madrid, cidade de encontros". O congreso estivo caracterizado pola súa versatilidade, interdisciplinariedade e a súa alta participación, pois nel puidéronse encontrar máis de 200 persoas vidas de todos os recunchos do mundo. Dos diferentes momentos que as persoas participantes viviron durante esta semana intensa, cabe mencionarmos a visita que realizamos á Real Biblioteca do Mosteiro do Escorial. Nesta xornada, puidemos gozar dunha visita guiada polo mosteiro e pola biblioteca e tivemos a oportunidade de poder apreciar o valor e a dimensionalidade dun dos manuscritos medievais máis importantes do noso patrimonio cultural medieval: o coñecido Códice Rico das Cantigas de Santa María de Afonso X o Sabio.

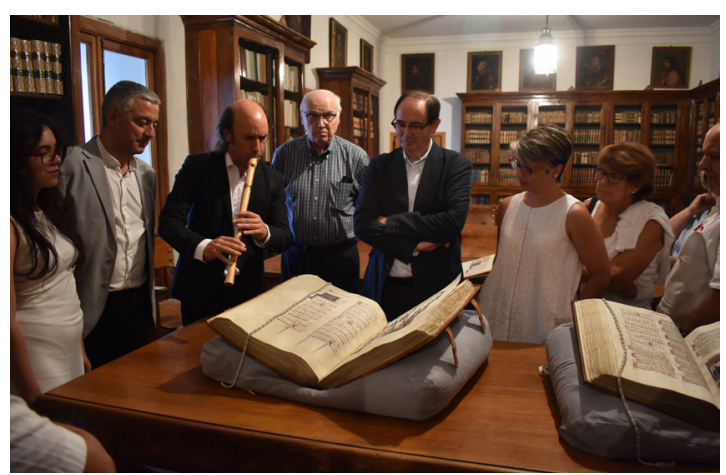

Ante o Códice rico das Cantigas de Santa María (en fronte do manuscrito, de esquerda á dereita: Carlos Núñez, Harvey L. Sharrer e José Luis del Valle Merino)

Ademais disto, dentro da biblioteca, os congresistas asistiron a un concerto ofrecido pola Escolanía escurialense, xunto con Carlos Núñez e os seus músicos e acompañados do profesor Havery L. Sharrer, quen recitou o prólogo das Cantigas durante o concerto.

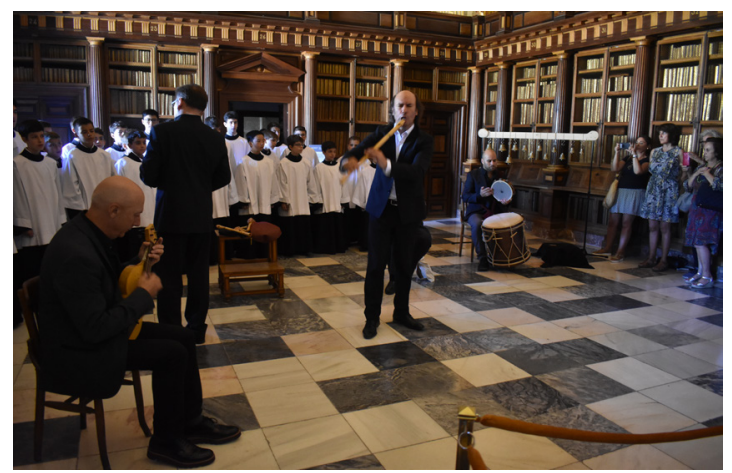

\footnotetext{
Universidade Complutense de Madrid, Centro de Estudos Galegos.

Correo-e: paulacou@ucm.es

2 Deste evento falouse devagar na crónica "A proxección da cultura galega desde o Centro de Estudos Galegos da UCM (2017-2018)”, contida no núm. 21 de Madrygal, pp. 409-412.
} 
Tamén debemos destacar a asemblea que se celebrou no día 13 setembro e na que interviñeron os socios da Asociación coa finalidade de elixir unha nova presidenta para AIEG. A profesora Maria Boguszewicz da Universidade de Varsovia sairía elixida tras esta reunión, polo que o próximo congreso da AEIG en 2021 terá lugar nesta cidade polaca.

Certamente, o congreso foi un encontro relevante para Galicia e a nosa lingua, non só polo altísimo nivel de cada un dos congresistas, senón tamén pola propia recepción que este tivo desde o punto de vista institucional, pois non sería posible a súa celebración sen o apoio da Universidad Complutense de Madrid, a Xunta de Galicia, a Real Biblioteca do Mosteiro do Escorial, o Ateneo e a Casa de Galicia de Madrid. A todas elas, agradecemos sinceramente a súa disposición e o bo facer no desenvolvemento deste evento internacional.

Tras o congreso, as actividades do CEG continuaron e puidemos asistir á conferencia do profesor e membro da comisión de onomástica da RAG Vicente Feijóo na Escola de Idiomas Jesús Maestro sobre o proxecto Toponimizate. Vicente falou sobre a importancia da toponimia e o desenvolvemento deste proxecto, unha aplicación que están elaborando e que servirá para que a cidadanía se implique na recollida de toda a nosa riqueza léxica en relación coa microtoponimia. A aplicación, de gran relevancia para o coñecemento do noso léxico e de gran potencial didáctico, contribuirá tamén a elaborarmos unha "cartografía colectiva", unha vez que permitirá incorporar outro tipo de contidos relacionados con este campo, desde os máis estritamente lingüísticos, como a fonética, ata os máis culturais, coa recollida de lendas, parte relevante da nosa literatura oral. Vicente Feijóo, que xa nos visitara no XII Congreso da AIEG cunha comunicación relacionada con este proxecto, deixou claras as posibilidades que nos ofrece esta nova aplicación.

Tamén neste mes de novembro, e desde o CEG, convidamos o director da editorial Galaxia, Francisco Castro, para que impartise ao alumnado, de galego e de portugués, un taller literario. Neste sentido, cabe salientarmos a boa disposición de Francisco, quen durante dúas horas levou a cabo un taller moi entretido, motivador, e que finalizou cunha moi boa recepción por parte do público asistente. Sen dúbida, a combinación da imaxinación e das letras nesta mesma sesión permitiron espertar en máis dun as ganas de ler e escribir máis.

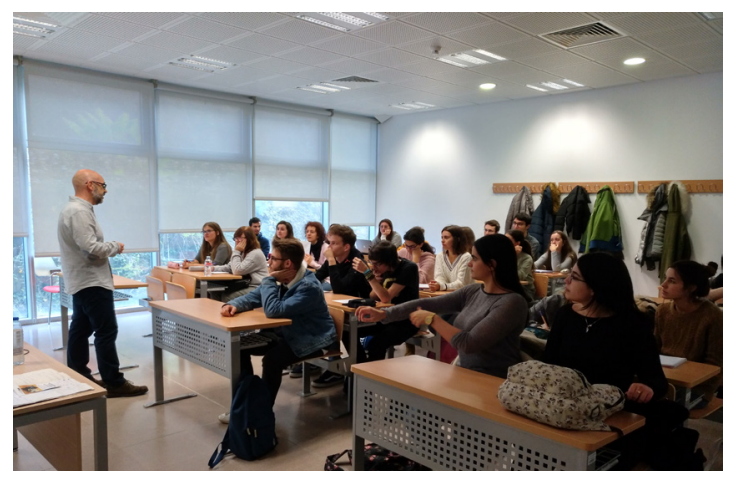

Francisco Castro introducindo o taller de creación literaria ao alumnado

Xa contra finais de ano e con motivo da preparación do Xacobeo 21, tivo lugar en Santiago de Compostela o I Simposio Internacional Os estudos Galegos Camiño do Xacobeo 21. Estas xornadas tiveron lugar na Cidade da Cultura en decembro de 2018 e a elas asistiron todas as persoas que espalladas polo mundo contribúen ao coñecemento e á difusión da lingua e da cultura galegas, nomeadamente os Centros de Estudos Galegos dos diferentes lectorados. Desde o CEG de Madrid, os encagardos de o representar foron Ricardo Pichel e quen subscribe esta crónica. A finalidade deste simposio consistiu en comezar a definir diferentes estratexias que permitan desde o exterior contribuír á difusión e coñecemento do fenómeno xacobeo, nomeadamente do camiño de Santiago de Compostela. Neste sentido, os axentes que estamos no exterior puidemos aproveitar o simposio para compartir cos demais integrantes diferentes ideas e eixos, co obxectivo de patrocinar o Xacobeo 21.

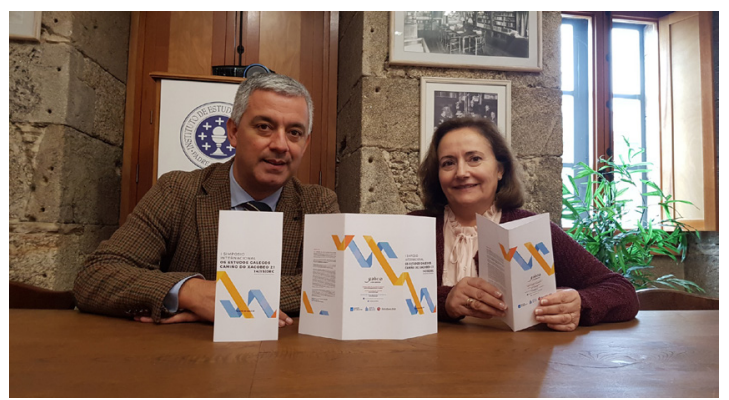

Valentín García Gómez e María Lourdes Batán Aira presentando o I Simposio Internacional Os estudos Galegos Camiño do Xacobeo 21 (fonte: Cultura.gal)

Tras este simposio, en febreiro de 2019 presentouse na Casa de Galicia o número 6 da revista Olga, dedicado ao grupo musical Voces ceibes no seu 50 aniversario e do que Vicente 
Araguas, director da revista Olga, formaba parte. Este volume, prologado polo propio Vicente, recorda con especial cariño a este grupo, conformado na súa época como un fenómeno totalmente contestatario e que, de certo, xa forma parte do noso patrimonio cultural.

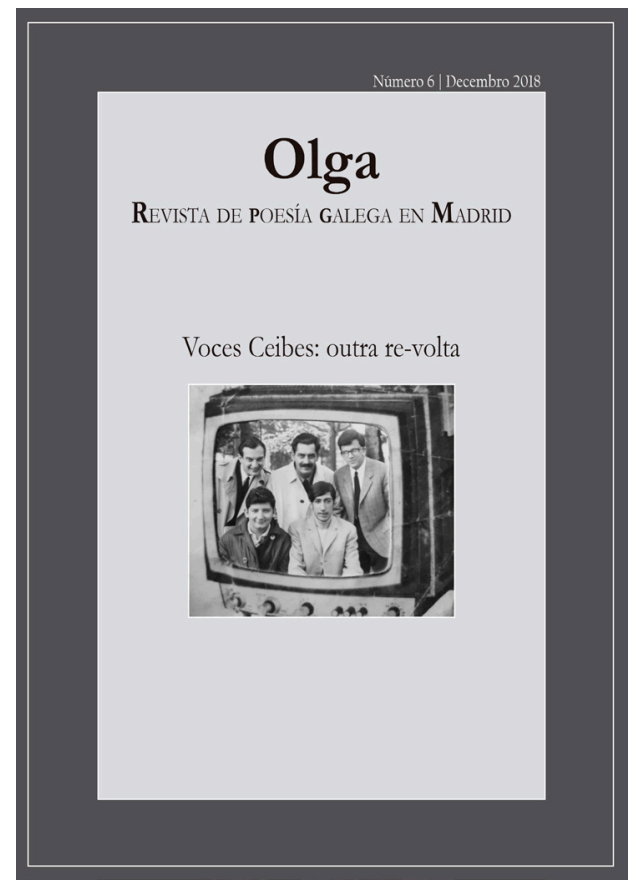

Tamén en febreiro, o CEG colaborou co Grupo Bilbao na celebración do día de Rosalía de Castro. Como é costume, o acto tivo lugar na casa da rúa Ballesta, onde Rosalía e o seu home Murguía viviron nos anos 50 do século XIX. Aquí, e tras un pequeno bosquexo sobre a vida da poeta por parte de Vicente Araguas, os asistentes recitamos unha serie de poemas e escritos da autora. Finalmente, camiñamos ata a igrexa de San Ildefonso, onde o matrimonio casou.

Unha vez iniciado o segundo cuatrimestre, organizamos un obradoiro de regueifa para o alumnado de galego e de portugués titulado Erre que erre: obradoiro de regueifa e improvisación oral, que tivo lugar na Facultade de Filoloxía da UCM en marzo de 2019. O taller foi levado a cabo pola regueifeira Alba María, quen tras unha breve exposición sobre a orixe da regueifa, procedeu a explicar desde un punto de vista técnico a composición deste xénero. Con estes breves apuntamentos previos, o alumnado puido regueifar creando e cantando as súas propias composicións, ao tempo que aprenderon máis do patrimonio cultural galego. $O$ coñecemento desta área espertou o interese do alumnado e foi unha actividade moi ben recibida.

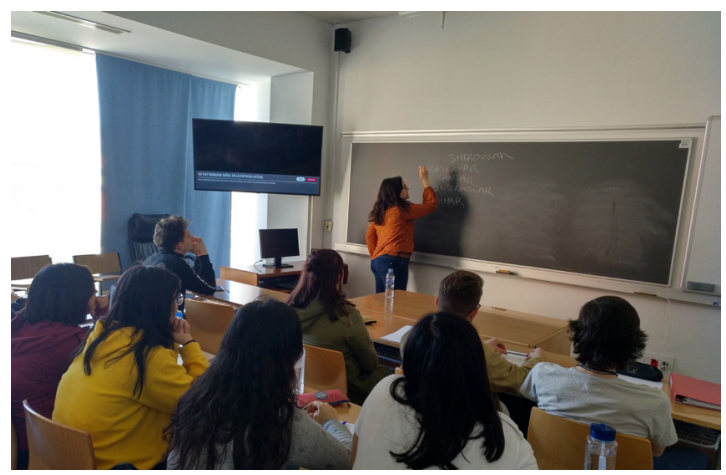

A regueifeira Alba María explicando as partes das que se compón unha regueifa

Continuando coa poesía, a Facultade de Filoloxía da UCM homenaxeou o poeta catalán Joan Margarit elaborando un volume con poemas do propio autor traducidos a diferentes linguas. Entre estas, podemos encontrar a colaboración da lectora con varios poemas verquidos ao galego. Tras a súa elaboración, a facultade convidou o poeta o 21 de marzo para vir e falar do que mellor coñece: o acto da escrita. A entrevista ao autor, que se desenvolveu nun espazo repleto, foi un acto interesante e reflexivo grazas ás intervencións do propio Margarit.

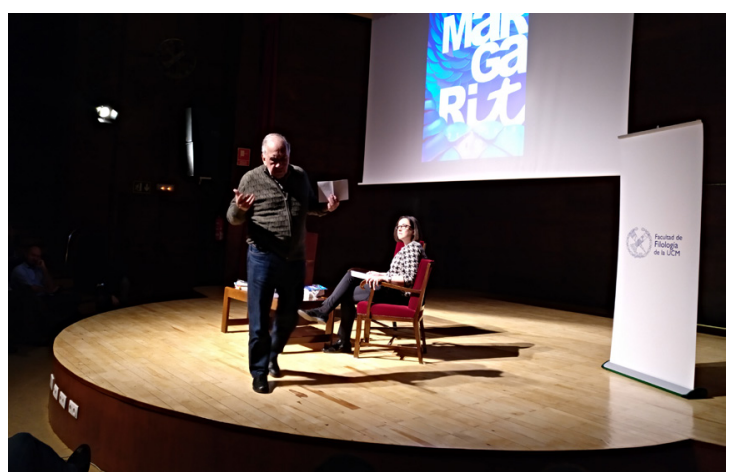

O poeta Joan Margarit nunha das súas intervencións

A continuación, colaboramos na conferencia que tivo lugar en abril por parte do profesor Jorge Urrutia, ofrecida especialmente para o alumnado que cursaba o Mestrado en Estudos Literarios. Nela, Urrutia expuxo o labor literario e editorial que se levou a cabo durante o exilio español, producido durante a guerra e posguerra civís, así como os diferentes tipos de exilio que existen, os temas máis comúns que se repiten ao longo da escrita dos exiliados e a súa relación con España. Durante a súa 
exposición, Urrutia adicou un tempo para dar a coñecer aquelas publicacións da emigración galega como De mar a mar (1942), Correo literario (1943-1944), Galeúzca (1945) e Galicia emigrante (1954-1959), todas elas arxentinas; ou outras como Saudade (1942) e Vieiros (1959), ambas as dúas mexicanas.

Polo que concirne novamente ás actividades de aula levadas a cabo polo CEG, este ano tamén decidimos continuar coa actividade Un ollar por Madrid, visto o éxito da primeira edición, debido a súa enorme visibilidade $\mathrm{e}$ as vantaxes que posúe desde o punto de vista didáctico. Este ano o CEG, xunto coa profesora de portugués Maria Colom, organizamos novamente esta exposición de textos e fotografías. A actividade, do mesmo xeito que na convocatoria do curso pasado 2017-18, consistiu en que o alumnado escribise un texto libre inspirado nalgún lugar de Madrid, ao que lle debían tirar unha fotografía para acompañar o escrito. Tras a recollida, a revisión e a impresión de todos os materiais, o alumnado voluntario expuxo nuns paneis os seus textos, animando ao público a ollaren e votaren polos seus textos favoritos. Os textos gañadores, do mesmo xeito que na edición anterior, son publicados en Madrygal, en concreto neste volume.

Tras esta experiencia, o CEG celebrou o Día das Letras Galegas, dedicadas este ano á figura do historiador Antón Fraguas, mediante un acto en colaboración co Ateneo de Madrid. A homenaxe estivo iniciada pola conferencia de Malores Villanueva sobre a vida e obra do autor, para logo finalizar cun recital poético coordinado polo poeta Vicente Araguas.

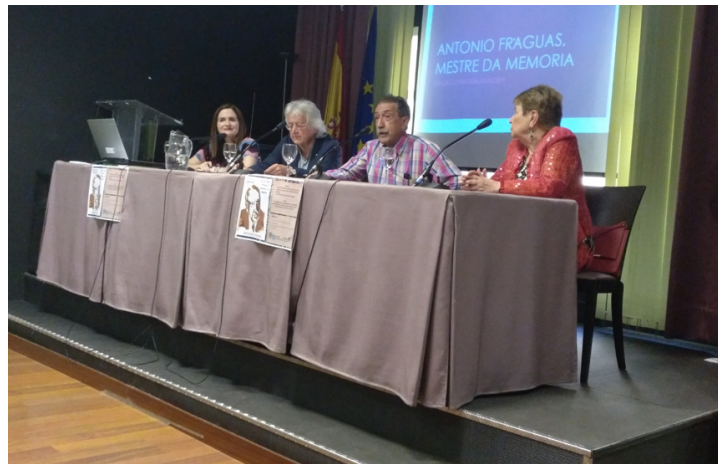

Na conferencia sobre Antonio Fraguas, de esquerda á dereita: Malores Villanueva, Manuel Pereira Valcárcel, Vicente Araguas e Pepa Nieto

Por último, O CEG tamén tivo tempo para traballar no campo da investigación e así o fixemos Carmen Mejía mais eu, pois asistimos e participamos a un par de congresos durante este curso académico. Por unha parte, asistimos ao $4^{\circ}$ Festival atlántico del género negro Tenerife Noir a finais de marzo do 2019. A nosa contribución, que será publicada posteriormente en forma de artigo en diferentes medios, versou sobre a novela negra en Galicia, concretamente nas obras Conduce rápido e Dime algo sucio do autor galego Diego Ameixeiras. Nesta nosa comunicación, analizamos o espazo urbano e o grao de hostilidade que este ten dentro da novela negra de Ameixeiras. Os días en Tenerife foron proveitosos, pois puidemos espertar o interese doutras persoas por Galicia e pola literatura galega, ao mesmo tempo que nós tamén puidemos coñecer outras realidades dentro do ámbito marcado polo festival.

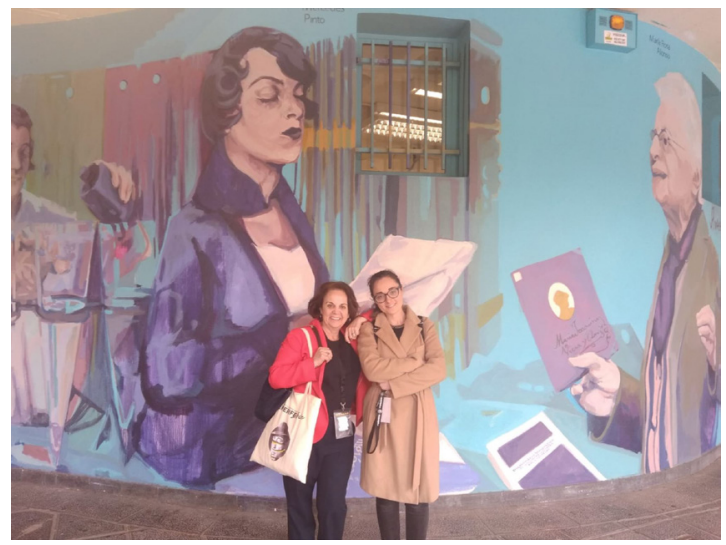

Carmen Mejía e Paula Cousillas diante dun mural feminista na Universidad de La Laguna

Por outra parte, en maio puidemos participar no Congreso Viajes reales, viajes imaginarios: textos, imágenes, metáforas, celebrado en Madrid na facultade de filoloxía da UCM, coa comunicación $O$ camiño de Santiago: unha viaxe imprescindible, na que analizamos a visión que Álvaro Cunqueiro reflicte nunha serie de artigos seus que publicara en vida no xornal Faro de Vigo por volta dos anos 60 sobre o camiño e, en concreto, sobre a etapa galega do camiño francés, desde O Cebreiro ata Santiago de Compostela. Esta foi unha boa oportunidade para darmos a coñecer o culto xacobeo e o camiño como parte esencial do patrimonio material e inmaterial da cultura galega.

Finalmente, e tendo en conta toda esta descrición, coidamos que o CEG de Madrid traballou nunha boa dirección, pois este ano implicouse intensamente na difusión de diferentes actividades, desde obradoiros ata comunicacións, co obxectivo de proxectar en Madrid e noutras latitudes unha imaxe diversa á par que interesante do fenómeno galego. 